Article

\title{
Convergence Theorems for Generalized Viscosity Explicit Methods for Nonexpansive Mappings in Banach Spaces and Some Applications
}

\author{
Pongsakorn Sunthrayuth ${ }^{1}$, Nuttapol Pakkaranang ${ }^{2,3}$, Poom Kumam ${ }^{2,3}$ (D), \\ Phatiphat Thounthong ${ }^{4, *(D)}$ and Prasit Cholamjiak ${ }^{5, *}$ \\ 1 Department of Mathematics and Computer Science, Faculty of Science and Technology, Rajamangala \\ University of Technology Thanyaburi (RMUTT), Thanyaburi, Pathumthani 12110, Thailand; \\ pongsakorn_su@rmutt.ac.th \\ 2 KMUTTFixed Point Research Laboratory, Room SCL 802 Fixed Point Laboratory, Science Laboratory \\ Building, Department of Mathematics, Faculty of Science, King Mongkut's University of Thonburi \\ (KMUTT), 126 Pracha-Uthit Road, Bang Mod, Thung Khru, Bangkok 10140, Thailand; \\ nuttapol.pakka@gmail.com (N.P.); poom.kum@kmutt.ac.th (P.K.) \\ 3 KMUTT-Fixed Point Theory and Applications Research Group (KMUTT-FPTA), \\ Theoretical and Computational Science Center (TaCS), Science Laboratory Building, Faculty of Science, \\ King Mongkut's University of Technology Thonburi (KMUTT), 126 Pracha-Uthit Road, Bang Mod, \\ Thung Khru, Bangkok 10140, Thailand \\ 4 Renewable Energy Research Centre \& Department of Teacher Training in Electrical Engineering, \\ Faculty of Technical Education, King Mongkut's University of Technology North Bangkok (KMUTNB), \\ Wongsawang, Bangsue, Bangkok 10800, Thailand \\ 5 School of Science, University of Phayao, Phayao 56000, Thailand \\ * Correspondence: phatiphat.t@fte.kmutnb.ac.th (P.T.); prasitch2008@yahoo.com (P.C.)
}

Received: 17 December 2018; Accepted: 3 February 2019; Published: 11 February 2019

\begin{abstract}
In this paper, we introduce a generalized viscosity explicit method (GVEM) for nonexpansive mappings in the setting of Banach spaces and, under some new techniques and mild assumptions on the control conditions, prove some strong convergence theorems for the proposed method, which converge to a fixed point of the given mapping and a solution of the variational inequality. As applications, we apply our main results to show the existence of fixed points of strict pseudo-contractions and periodic solutions of nonlinear evolution equations and Fredholm integral equations. Finally, we give some numerical examples to illustrate the efficiency and implementation of our method.
\end{abstract}

Keywords: nonexpansive mapping; Banach space; strong convergence; viscosity iterative method; nonlinear evolution equation; Fredholm integral equation

MSC: 47H09; 47H10; 47J25; 47J05

\section{Introduction}

In the real world, many engineering and science problems can be reformulated as ordinary differential equations. Several numerical methods have been developed for solving ordinary differential equations (ODEs) by numerous authors. The major method in order to solve ODEs is the implicit midpoint rule, also well known as the second-order Runge-Kutta method or improved the Euler method. It is a forceful numerical method for numerically solving ODEs (in particular, stiff equations) (see [1-6]) and differential algebraic equations (see [4]). Consider the following initial value problem for the following time-dependent ordinary differential equation: 


$$
\left\{\begin{array}{l}
x^{\prime}(t)=f(x(t)) \\
x\left(t_{0}\right)=x_{0}
\end{array}\right.
$$

where $f: \mathbb{R}^{N} \rightarrow \mathbb{R}^{N}$ is a continuous function. The implicit midpoint method is an implicit method, which is given by the following finite difference scheme [7]:

$$
\left\{\begin{array}{l}
y_{0}=x_{0}, \\
y_{n+1}=y_{n}+h f\left(\frac{y_{n}+y_{n+1}}{2}\right), \forall n \geq 0,
\end{array}\right.
$$

where $h>0$ is a step size. It is known that, if $f: \mathbb{R}^{N} \rightarrow \mathbb{R}^{N}$ is Lipschitz continuous and sufficiently smooth, then $\left\{y_{n}\right\}$ converges to the solution of Equation (1) as $h \rightarrow 0$ uniformly over $t \in\left[t_{0}, t^{*}\right]$ for any fixed $t^{*}>0$. If we write the function $f$ in the form $f=I-T$, where $T$ is a nonlinear mapping, then equilibrium problems involving differential Equation (1) is the fixed point problem $x=T x$. Following the procedure (2), $\mathrm{Xu}$ et al. [8] introduced two equivalent algorithms to approximate the fixed point of a nonexpansive mapping in a Hilbert space $H$ as follows:

$$
\begin{gathered}
x_{n+1}=x_{n}-t_{n}\left[\frac{x_{n}+x_{n+1}}{2}-T\left(\frac{x_{n}+x_{n+1}}{2}\right)\right], \forall n \geq 0, \\
x_{n+1}=\left(1-t_{n}\right) x_{n}+t_{n} T\left(\frac{x_{n}+x_{n+1}}{2}\right), \forall n \geq 0,
\end{gathered}
$$

for any $x_{0} \in H$, where $\left\{t_{n}\right\}_{n=1}^{\infty} \subset(0,1)$ is a sequence.

On the other hand, since, in 2000, Moudafi [9] introduced viscosity approximation methods for fixed point problems in Hilbert spaces, some authors have obtained some convergence theorems of viscosity approximation methods to show the existence of fixed points of some kinds of nonlinear mappings and solutions of nonlinear problems (see, for example, [10-20]). Especially, in 2015, $\mathrm{Xu}$ et al. [8] combined the Moudafi viscosity method [9] with the implicit midpoint method for a nonexpansive mapping in Hilbert spaces as follows:

$$
x_{n+1}=\alpha_{n} f\left(x_{n}\right)+\left(1-\alpha_{n}\right) T\left(\frac{x_{n}+x_{n+1}}{2}\right), \forall n \geq 1,
$$

where $f$ is a contraction and $\left\{\alpha_{n}\right\} \subset(0,1)$ is a sequence. They also proved that $\left\{x_{n}\right\}$ generated by (5) converges strongly to a point $x^{*} \in F(T)$, which is the unique solution of the following variational inequality problem:

$$
\left\langle(f-I) x^{*}, z-x^{*}\right\rangle \leq 0, \forall z \in F(T) .
$$

Recently, Ke and Ma [21] improved the VIMRby replacing the midpoint by any point of the interval $\left[x_{n}, x_{n+1}\right]$. They constructed the so-called method generalized viscosity implicit rules for a nonexpansive mapping as follows:

$$
x_{n+1}=\alpha_{n} f\left(x_{n}\right)+\left(1-\alpha_{n}\right) T\left(s_{n} x_{n}+\left(1-s_{n}\right) x_{n+1}\right), \quad \forall n \geq 1 .
$$

They showed that $\left\{x_{n}\right\}$ defined by (7) converges strongly to $x^{*} \in F(T)$, which solves the variational inequality problem (6).

In fact, the computation by the implicit midpoint methods is not an easy work in practice. Therefore, we consider the explicit midpoint method proposed by the framework of the finite difference $[22,23]:$

$$
\left\{\begin{array}{l}
y_{0}=x_{0}, \\
\bar{y}_{n+1}=y_{n}+h f\left(y_{n}\right), \\
y_{n+1}=y_{n}+h f\left(\frac{y_{n}+\bar{y}_{n+1}}{2}\right), \forall n \geq 0 .
\end{array}\right.
$$


It is easy to see that the explicit midpoint method calculates the state of a system at the next time from the state of the system at the current time (see [22,24]).

In 2017, Marino et al. [25] applied the sequence (7) and the explicit midpoint method (8) to established the following so-called general viscosity explicit rule for quasi-nonexpansive mappings $T$ in Hilbert spaces:

$$
\left\{\begin{array}{l}
\bar{x}_{n+1}=\beta_{n} x_{n}+\left(1-\beta_{n}\right) T x_{n}, \\
x_{n+1}=\alpha_{n} f\left(x_{n}\right)+\left(1-\alpha_{n}\right) T\left(s_{n} x_{n}+\left(1-s_{n}\right) \bar{x}_{n+1}\right), \quad \forall n \geq 1,
\end{array}\right.
$$

where $f$ is a contraction and $\left\{\alpha_{n}\right\},\left\{\beta_{n}\right\}$, and $\left\{s_{n}\right\}$ are the sequences in $(0,1)$. They proved, under suitable conditions on the sequence parameters, that the generalized viscosity explicit rule (9) strongly converges to the set of $F(T)$, which is also the solution of the variational inequality problem (6).

The main objective of this paper is to introduce a generalized viscosity explicit rule (9) for nonexpansive mappings in Banach spaces. Some strong convergence theorems of the proposed algorithm are proven under new techniques and some mild assumption on the control conditions. As applications, we apply our main result to the fixed point problem of strict pseudo-contractions, a periodic solution of a nonlinear evolution equation, and a nonlinear Fredholm integral equation. Finally, some numerical examples that show the efficiency and implementation of our algorithm are presented. The results presented in the paper extend and improve the main results of Ke and Ma [21], Marino et al. [25], and previously known results in the earlier and recent literature to Banach spaces.

\section{Preliminaries}

Let $E$ and $E^{*}$ be a real Banach space and the dual space of $E$, respectively. The normalized duality mapping $J: E \rightarrow 2^{E^{*}}$ is defined by:

$$
J(x)=\left\{\bar{x} \in E^{*}:\langle x, \bar{x}\rangle=\|x\|^{2},\|\bar{x}\|=\|x\|\right\}, \forall x \in E,
$$

where $\langle\cdot, \cdot\rangle$ denotes the duality pairing between $E$ and $E^{*}$. If $E:=H$ is a real Hilbert space, then $J=I$ is the identity mapping and if $E$ is smooth, then $J$ is single-valued, which is denoted by $j$.

The modulus of convexity of $E$ is the function $\delta:(0,2] \rightarrow[0,1]$ defined by:

$$
\delta(\epsilon)=\inf \left\{1-\frac{\|x+y\|}{2}: x, y \in E,\|x\|=\|y\|=1,\|x-y\| \geq \epsilon\right\}
$$

A Banach space $E$ is said to be uniformly convex if $\delta_{E}(\epsilon)>0$ for all $\epsilon \in(0,2]$. The modulus of smoothness of $E$ is the function $\rho_{E}: \mathbb{R}^{+}:=[0, \infty) \rightarrow \mathbb{R}^{+}$defined by:

$$
\rho_{E}(\tau)=\sup \left\{\frac{\|x+\tau y\|+\|x-\tau y\|}{2}-1: x, y \in E,\|x\|=\|y\|=1\right\} \text {. }
$$

The space $E$ is said to be uniformly smooth if $\frac{\rho_{E}(\tau)}{\tau} \rightarrow 0$ as $\tau \rightarrow 0$. Suppose that $1<q \leq 2$, then $E$ is said to be $q$-uniformly smooth if there exists $c>0$ such that $\rho_{E}(\tau) \leq c \tau^{q}$ for all $\tau>0$. It is well known that, if $q$ is uniformly smooth, then $E$ is uniformly smooth [26]. A typical example of a uniformly convex and uniformly smooth Banach spaces is $l_{p}$, where $p>1$. More precisely, $l_{p}$ is $\min \{p, 2\}$-uniformly smooth for any $p>1$.

Recall that a mapping $T: C \rightarrow C$ is said to be: nonexpansive if

$$
\|T x-T y\| \leq\|x-y\|, \forall x, y \in C
$$

A mapping $f: C \rightarrow C$ is said to be a strict contraction if there exists a constant $\alpha \in(0,1)$ satisfying:

$$
\|f(x)-f(y)\| \leq \alpha\|x-y\|, \forall x, y \in C
$$


We use $\Pi_{C}$ to denote the collection of all contractions from $C$ into itself. Note that each $f \in \Pi_{C}$ has a unique fixed point in $C$.

Lemma 1. ([27]) Let E be a real Banach space. Then, for each $x, y \in E$, we have:

$$
\|x+y\|^{2} \leq\|x\|^{2}+2\langle y, j(x+y)\rangle
$$

where $j(x+y) \in J(x+y)$.

Lemma 2. ([28]) Given $r>0$ and $p>1$ are fixed real numbers in Banach space E, then the following statements are equivalent:

(1) E is uniformly convex.

(2) There is a strictly-increasing, continuous, and convex function $\phi: \mathbb{R}^{+} \rightarrow \mathbb{R}^{+}$such that $\phi(0)=0$ and:

$$
\|t x+(1-t) y\|^{p} \leq t\|x\|^{p}+(1-t)\|y\|^{p}-t(1-t) \phi(\|x-y\|)
$$

for all $x, y \in B_{r}[0]:=\{x \in E:\|x\| \leq r\}$

The following lemma can be found in [29-31].

Lemma 3. Let $C$ be a closed, convex subset and nonempty uniformly smooth in $E$. Let $T$ be a nonexpansive mapping with $F(T) \neq \varnothing$ and $f \in \Pi_{C}$. Then the sequence $\left\{z_{t}\right\}$ defined by $z_{t}=t f\left(z_{t}\right)+(1-t) T z_{t}$ for all $t \in(0,1)$ converges strongly to a point $x^{*} \in F(T)$, which solves the variational inequality problem:

$$
\left\langle f\left(x^{*}\right)-x^{*}, j\left(z-x^{*}\right)\right\rangle \leq 0, \forall f \in \Pi_{C}, z \in F(T) .
$$

Lemma 4. ([32]) Let $C$ be a closed, convex subset and nonempty in E, which has the uniformly Gâteaux differentiable norm and $T$ is a nonexpansive mapping with $F(T) \neq \varnothing$. Suppose that $\left\{z_{t}\right\}$ strongly converges to $x^{*} \in F(T)$, where $\left\{z_{t}\right\}$ is defined by $z_{t}=t f\left(z_{t}\right)+(1-t) T z_{t}$ for all $t \in(0,1)$. Suppose that $\left\{x_{n}\right\}$ is bounded in $C$ such that:

$$
\lim _{n \rightarrow \infty}\left\|x_{n}-T x_{n}\right\|=0
$$

Then, we have:

$$
\limsup _{n \rightarrow \infty}\left\langle f\left(x^{*}\right)-x^{*}, j\left(x_{n}-x^{*}\right)\right\rangle \leq 0
$$

Lemma 5. ([33,34]) Assume that $\left\{a_{n}\right\}$ is a positive real sequence such that:

$$
a_{n+1} \leq\left(1-\gamma_{n}\right) a_{n}+\gamma_{n} \delta_{n}, \forall n \geq 0
$$

where $\left\{\gamma_{n}\right\} \in(0,1)$ and $\left\{\delta_{n}\right\} \in \mathbb{R}$ such that:

(i) $\sum_{n=0}^{\infty} \gamma_{n}=\infty$;

(ii) $\quad \lim \sup _{n \rightarrow \infty} \delta_{n} \leq 0$ or $\sum_{n=0}^{\infty}\left|\gamma_{n} \delta_{n}\right|<\infty$.

Then, $\lim _{n \rightarrow \infty} a_{n}=0$.

In order to prove our main result with new techniques, we needed the following Maingé lemma [35]:

Lemma 6. Given $\left\{a_{n}\right\}$ are real sequences so that there exists a subsequence $\left\{n_{i}\right\}$ of $\{n\}$ such that $a_{n_{i}}<a_{n_{i}+1}$ for all $i \in \mathbb{N}$, then there exists an increasing sequence $\left\{m_{k}\right\} \subset \mathbb{N}$ that $m_{k} \rightarrow \infty$, and the following properties are satisfied for all numbers $k \in \mathbb{N}$ : 


$$
a_{k} \leq a_{m_{k}+1}, \quad a_{m_{k}} \leq a_{m_{k}+1}
$$

where $m_{k}:=\max \left\{j \leq k: a_{j} \leq a_{j+1}\right\}$.

\section{The Main Results}

First, we prove a lemma for our main results.

Lemma 7. Let $C$ be a nonempty closed and convex subset of a real Banach space $E$. Let $T$ be a nonexpansive mapping with $F(T) \neq \varnothing$ and $f \in \Pi_{C}$ with coefficient $\alpha \in(0,1)$. For any $x_{1} \in C$, let $\left\{x_{n}\right\}$ be a sequence generated by:

$$
\left\{\begin{array}{l}
\bar{x}_{n+1}=\beta_{n} x_{n}+\left(1-\beta_{n}\right) T x_{n}, \\
x_{n+1}=\alpha_{n} f\left(x_{n}\right)+\left(1-\alpha_{n}\right) T\left(s_{n} x_{n}+\left(1-s_{n}\right) \bar{x}_{n+1}\right), \quad \forall n \geq 1,
\end{array}\right.
$$

where $\left\{\alpha_{n}\right\},\left\{\beta_{n}\right\}$, and $\left\{s_{n}\right\}$ are the sequences in $(0,1)$. Then, $\left\{x_{n}\right\}$ is bounded.

Proof. For each $n \geq 1$, we put $z_{n}:=s_{n} x_{n}+\left(1-s_{n}\right) \bar{x}_{n+1}$. Let $z \in F(T)$; we have:

$$
\begin{aligned}
\left\|z_{n}-z\right\| & =\left\|s_{n}\left(x_{n}-z\right)+\left(1-s_{n}\right)\left(\bar{x}_{n+1}-z\right)\right\| \\
& \leq s_{n}\left\|x_{n}-z\right\|+\left(1-s_{n}\right)\left\|\bar{x}_{n+1}-z\right\| \\
& \leq s_{n}\left\|x_{n}-z\right\|+\left(1-s_{n}\right)\left(\beta_{n}\left\|x_{n}-z\right\|+\left(1-\beta_{n}\right)\left\|T x_{n}-z\right\|\right) \\
& \leq s_{n}\left\|x_{n}-z\right\|+\left(1-s_{n}\right) \beta_{n}\left\|x_{n}-z\right\|+\left(1-s_{n}\right)\left(1-\beta_{n}\right)\left\|x_{n}-z\right\| \\
& =\left\|x_{n}-z\right\| .
\end{aligned}
$$

It follows that:

$$
\begin{aligned}
\left\|x_{n+1}-z\right\| & =\left\|\alpha_{n}\left(f\left(x_{n}\right)-f(z)\right)+\alpha_{n}(f(z)-z)+\left(1-\alpha_{n}\right)\left(T z_{n}-z\right)\right\| \\
& \leq \alpha_{n}\left\|f\left(x_{n}\right)-f(z)\right\|+\alpha_{n}\|f(z)-z\|+\left(1-\alpha_{n}\right)\left\|T z_{n}-z\right\| \\
& \leq \alpha_{n} \alpha\left\|x_{n}-z\right\|+\left(1-\alpha_{n}\right)\left\|z_{n}-z\right\|+\alpha_{n}\|f(z)-z\| \\
& =\left(1-(1-\alpha) \alpha_{n}\right)\left\|x_{n}-z\right\|+(1-\alpha) \alpha_{n} \frac{\|f(z)-z\|}{1-\alpha} \\
& \leq \max \left\{\left\|x_{n}-z\right\|, \frac{\|f(z)-z\|}{1-\alpha}\right\} .
\end{aligned}
$$

By induction, we have:

$$
\left\|x_{n}-z\right\| \leq \max \left\{\left\|x_{1}-z\right\|, \frac{\|f(z)-z\|}{1-\alpha}\right\}, \forall n \geq 1
$$

Hence, $\left\{x_{n}\right\}$ is bounded. This completes the proof.

Theorem 1. Let $C$ be closed, convex subset and nonempty uniformly convex and uniformly smooth in E. Let $T$ be a nonexpansive mapping with $F(T) \neq \varnothing$ and $f \in \Pi_{C}$ with coefficient $\alpha \in(0,1)$. Suppose that $\left\{\alpha_{n}\right\},\left\{\beta_{n}\right\}$ and $\left\{s_{n}\right\}$ are the sequences in $(0,1)$ satisfying the following conditions:

(C1) $\lim _{n \rightarrow \infty} \alpha_{n}=0$ and $\sum_{n=1}^{\infty} \alpha_{n}=\infty$;

(C2) $0<\liminf _{n \rightarrow \infty} \beta_{n}\left(1-\beta_{n}\right)\left(1-s_{n}\right)$.

Then, $\left\{x_{n}\right\}$ generated by (10) converges strongly to a point $x^{*} \in F(T)$, which solves the variational inequality problem:

$$
\left\langle f\left(x^{*}\right)-x^{*}, j\left(z-x^{*}\right)\right\rangle \leq 0, \forall z \in F(T) .
$$


Proof. Let $x^{*} \in F(T)$. Since $z_{n}:=s_{n} x_{n}+\left(1-s_{n}\right) \bar{x}_{n+1}$, by the convexity of $\|\cdot\|^{2}$ and Lemma 2, we have:

$$
\begin{aligned}
\left\|T z_{n}-x^{*}\right\|^{2} \leq & \left\|z_{n}-x^{*}\right\|^{2} \\
= & \left\|s_{n}\left(x_{n}-x^{*}\right)+\left(1-s_{n}\right)\left(\bar{x}_{n+1}-x^{*}\right)\right\|^{2} \\
\leq & s_{n}\left\|x_{n}-x^{*}\right\|^{2}+\left(1-s_{n}\right)\left\|\bar{x}_{n+1}-x^{*}\right\|^{2} \\
= & s_{n}\left\|x_{n}-x^{*}\right\|^{2}+\left(1-s_{n}\right)\left\|\beta_{n}\left(x_{n}-x^{*}\right)+\left(1-\beta_{n}\right)\left(T x_{n}-x^{*}\right)\right\|^{2} \\
\leq & s_{n}\left\|x_{n}-x^{*}\right\|^{2}+\left(1-s_{n}\right)\left[\beta_{n}\left\|x_{n}-x^{*}\right\|^{2}+\left(1-\beta_{n}\right)\left\|T x_{n}-x^{*}\right\|^{2}\right. \\
& \left.-\beta_{n}\left(1-\beta_{n}\right) \phi\left(\left\|x_{n}-T x_{n}\right\|\right)\right] \\
\leq & \left\|x_{n}-x^{*}\right\|^{2}-\beta_{n}\left(1-\beta_{n}\right)\left(1-s_{n}\right) \phi\left(\left\|x_{n}-T x_{n}\right\|\right) .
\end{aligned}
$$

It follows from Lemma 1 and (12) that:

$$
\begin{aligned}
& \left\|x_{n+1}-x^{*}\right\|^{2} \\
= & \left\|\alpha_{n}\left(f\left(x_{n}\right)-f\left(x^{*}\right)\right)+\alpha_{n}\left(f\left(x^{*}\right)-x^{*}\right)+\left(1-\alpha_{n}\right)\left(T z_{n}-x^{*}\right)\right\|^{2} \\
\leq & \left\|\alpha_{n}\left(f\left(x_{n}\right)-f\left(x^{*}\right)\right)+\left(1-\alpha_{n}\right)\left(T z_{n}-x^{*}\right)\right\|^{2}+2 \alpha_{n}\left\langle f\left(x^{*}\right)-x^{*}, j\left(x_{n+1}-x^{*}\right)\right\rangle \\
\leq \quad & \alpha_{n}\left\|f\left(x_{n}\right)-f\left(x^{*}\right)\right\|^{2}+\left(1-\alpha_{n}\right)\left\|T z_{n}-x^{*}\right\|^{2}+2 \alpha_{n}\left\langle f\left(x^{*}\right)-x^{*}, j\left(x_{n+1}-x^{*}\right)\right\rangle \\
\leq \quad & \alpha_{n}\left\|f\left(x_{n}\right)-f\left(x^{*}\right)\right\|^{2}+\left(1-\alpha_{n}\right)\left[\left\|x_{n}-x^{*}\right\|^{2}-\beta_{n}\left(1-\beta_{n}\right)\left(1-s_{n}\right) \phi\left(\left\|x_{n}-T x_{n}\right\|\right)\right] \\
& +2 \alpha_{n}\left\langle f\left(x^{*}\right)-x^{*}, j\left(x_{n+1}-x^{*}\right)\right\rangle \\
\leq & \left(1-\left(1-\alpha^{2}\right) \alpha_{n}\right)\left\|x_{n}-x^{*}\right\|^{2}-\left(1-\alpha_{n}\right) \beta_{n}\left(1-\beta_{n}\right)\left(1-s_{n}\right) \phi\left(\left\|x_{n}-T x_{n}\right\|\right) \\
& +2 \alpha_{n}\left\langle f\left(x^{*}\right)-x^{*}, j\left(x_{n+1}-x^{*}\right)\right\rangle .
\end{aligned}
$$

Now, we show that $\left\{x_{n}\right\}$ converges strongly to $x^{*}$ as $n \rightarrow \infty$ by considering two possible cases:

Case 1. Assume that there exists $n_{0} \in \mathbb{N}$ such that $\left\{\left\|x_{n}-x^{*}\right\|\right\}_{n=n_{0}}^{\infty}$ is non-increasing. This implies that $\left\{\left\|x_{n}-x^{*}\right\|\right\}_{n=1}^{\infty}$ is convergent. From (13), it follows that:

$$
\left(1-\alpha_{n}\right) \beta_{n}\left(1-\beta_{n}\right)\left(1-s_{n}\right) \phi\left(\left\|x_{n}-T x_{n}\right\|\right) \leq\left\|x_{n}-x^{*}\right\|^{2}-\left\|x_{n+1}-x^{*}\right\|^{2}+\alpha_{n} M,
$$

where $M=\sup _{n \geq 1}\left\{2\left\|f\left(x^{*}\right)-x^{*}\right\|\left\|x_{n+1}-x^{*}\right\|,\left(1-\alpha^{2}\right)\left\|x_{n}-x^{*}\right\|^{2}\right\}<\infty$. From the conditions (C1) and (C2), we have:

$$
\phi\left(\left\|x_{n}-T x_{n}\right\|\right) \rightarrow 0 \text { as } n \rightarrow \infty,
$$

which implies by the property of $\phi$ that:

$$
\left\|x_{n}-T x_{n}\right\| \rightarrow 0 \text { as } n \rightarrow \infty .
$$

Let:

$$
z_{t}=f\left(z_{t}\right)+(1-t) T z_{t}, \quad \forall t \in(0,1) .
$$

By Lemma $3,\left\{z_{t}\right\}$ converges strongly to $x^{*}$, which solves the variational inequality problem:

$$
\left\langle f\left(x^{*}\right)-x^{*}, j\left(z-x^{*}\right)\right\rangle \leq 0, \forall z \in F(T) .
$$

By (14) and Lemma 4, it follows that:

$$
\limsup _{n \rightarrow \infty}\left\langle f\left(x^{*}\right)-x^{*}, j\left(x_{n}-x^{*}\right)\right\rangle \leq 0 .
$$


Since:

$$
\begin{aligned}
\left\|T z_{n}-x_{n}\right\| & \leq\left\|T z_{n}-T x_{n}\right\|+\left\|T x_{n}-x_{n}\right\| \\
& \leq\left\|z_{n}-x_{n}\right\|+\left\|T x_{n}-x_{n}\right\| \\
& =\left(1-s_{n}\right)\left(1-\beta_{n}\right)\left\|T x_{n}-x_{n}\right\|+\left\|T x_{n}-x_{n}\right\| \\
& \leq 2\left\|x_{n}-T x_{n}\right\|,
\end{aligned}
$$

it follows from (14) that:

$$
\lim _{n \rightarrow \infty}\left\|T z_{n}-x_{n}\right\|=0
$$

Moreover, we note that:

$$
\begin{aligned}
\left\|x_{n+1}-x_{n}\right\| & \leq\left\|\alpha_{n}\left(f\left(x_{n}\right)-x_{n}\right)+\left(1-\alpha_{n}\right)\left(T z_{n}-x_{n}\right)\right\| \\
& \leq \alpha_{n}\left\|f\left(x_{n}\right)-x_{n}\right\|+\left(1-\alpha_{n}\right)\left\|T z_{n}-x_{n}\right\| .
\end{aligned}
$$

It follows from (16) that:

$$
\lim _{n \rightarrow \infty}\left\|x_{n+1}-x_{n}\right\|=0
$$

Furthermore, we have:

$$
\limsup _{n \rightarrow \infty}\left\langle f\left(x^{*}\right)-x^{*}, j\left(x_{n+1}-x^{*}\right)\right\rangle \leq 0 .
$$

From (13), we note that:

$$
\left\|x_{n+1}-x^{*}\right\|^{2} \leq\left(1-\left(1-\alpha^{2}\right) \alpha_{n}\right)\left\|x_{n}-x^{*}\right\|^{2}+2 \alpha_{n}\left\langle f\left(x^{*}\right)-x^{*}, j\left(x_{n+1}-x^{*}\right)\right\rangle .
$$

Applying Lemma 5, (18) and (19), we can conclude that $x_{n} \rightarrow x^{*}$ as $n \rightarrow \infty$.

Case 2. There exists a subsequence $\left\{n_{i}\right\}$ of $\{n\}$ such that:

$$
\left\|x_{n_{i}}-x^{*}\right\| \leq\left\|x_{n_{i+1}}-x^{*}\right\|, \quad \forall i \geq 1 .
$$

By Lemma 6, there exists a non-decreasing sequence $\left\{m_{k}\right\} \subset \mathbb{N}$ such that $m_{k} \rightarrow \infty$ and:

$$
\begin{gathered}
\left\|x_{m_{k}}-x^{*}\right\| \leq\left\|x_{m_{k}+1}-x^{*}\right\|, \\
\left\|x_{k}-x^{*}\right\| \leq\left\|x_{m_{k}+1}-x^{*}\right\|, \quad \forall k \geq 1 .
\end{gathered}
$$

Again, from (13), we have:

$$
\begin{aligned}
& \left(1-\alpha_{m_{k}}\right) \beta_{m_{k}}\left(1-\beta_{m_{k}}\right)\left(1-s_{m_{k}}\right) \phi\left(\left\|x_{m_{k}}-T x_{m_{k}}\right\|\right) \\
\leq & \left\|x_{m_{k}}-x^{*}\right\|^{2}-\left\|x_{m_{k}+1}-x^{*}\right\|^{2}+\alpha_{m_{k}} M \\
\leq & \alpha_{m_{k}} M
\end{aligned}
$$

which implies by the property of $\phi$ that:

$$
\left\|x_{m_{k}}-T x_{m_{k}}\right\| \rightarrow 0 \text { as } k \rightarrow \infty .
$$


Following the proof lines in Case 1, we can show that:

$$
\limsup _{k \rightarrow \infty}\left\langle f\left(x^{*}\right)-x^{*}, j\left(x_{m_{k}}-x^{*}\right)\right\rangle \leq 0 .
$$

Consequently, we have:

$$
\begin{aligned}
\left\|T z_{m_{k}}-x_{m_{k}}\right\| & \leq\left\|T z_{m_{k}}-T x_{m_{k}}\right\|+\left\|T x_{m_{k}}-x_{m_{k}}\right\| \\
& \leq\left\|z_{m_{k}}-x_{m_{k}}\right\|+\left\|T x_{m_{k}}-x_{m_{k}}\right\| \\
& =\left(1-s_{m_{k}}\right)\left(1-\beta_{m_{k}}\right)\left\|T x_{m_{k}}-x_{m_{k}}\right\|+\left\|T x_{m_{k}}-x_{m_{k}}\right\| \\
& \leq 2\left\|x_{m_{k}}-T x_{m_{k}}\right\| \rightarrow 0 \text { as } k \rightarrow \infty .
\end{aligned}
$$

It follows that:

$$
\begin{aligned}
\left\|x_{m_{k}+1}-x_{m_{k}}\right\| & \leq\left\|\alpha_{m_{k}}\left(f\left(x_{m_{k}}\right)-x_{m_{k}}\right)+\left(1-\alpha_{m_{k}}\right)\left(T z_{m_{k}}-x_{m_{k}}\right)\right\| \\
& \leq \alpha_{m_{k}}\left\|f\left(x_{m_{k}}\right)-x_{m_{k}}\right\|+\left(1-\alpha_{m_{k}}\right)\left\|T z_{m_{k}}-x_{m_{k}}\right\| \rightarrow 0 \text { as } k \rightarrow \infty .
\end{aligned}
$$

Therefore, we have:

$$
\limsup _{k \rightarrow \infty}\left\langle f\left(x^{*}\right)-x^{*}, j\left(x_{m_{k}+1}-x^{*}\right)\right\rangle \leq 0 .
$$

This together with (19) implies that:

$$
\begin{aligned}
& \left\|x_{m_{k}+1}-x^{*}\right\|^{2} \\
\leq & \left(1-\left(1-\alpha^{2}\right) \alpha_{m_{k}}\right)\left\|x_{m_{k}}-x^{*}\right\|^{2}+2 \alpha_{m_{k}}\left\langle f\left(x^{*}\right)-x^{*}, j\left(x_{m_{k}+1}-x^{*}\right)\right\rangle .
\end{aligned}
$$

We see that:

$$
\begin{aligned}
& \left(1-\alpha^{2}\right) \alpha_{m_{k}}\left\|x_{m_{k}}-x^{*}\right\|^{2} \\
\leq & \left\|x_{m_{k}}-x^{*}\right\|^{2}-\left\|x_{m_{k}+1}-x^{*}\right\|^{2}+2 \alpha_{m_{k}}\left\langle f\left(x^{*}\right)-x^{*}, j\left(x_{m_{k}+1}-x^{*}\right)\right\rangle \\
\leq & 2 \alpha_{m_{k}}\left\langle f\left(x^{*}\right)-x^{*}, j\left(x_{m_{k}+1}-x^{*}\right)\right\rangle .
\end{aligned}
$$

Since $\alpha_{m_{k}}>0$, we have $\lim _{k \rightarrow \infty}\left\|x_{m_{k}}-x^{*}\right\|=0$. Therefore, we have:

$$
\begin{aligned}
\left\|x_{k}-x^{*}\right\| & \leq\left\|x_{m_{k}+1}-x^{*}\right\| \\
& =\left\|x_{m_{k}}-x^{*}\right\|+\left\|x_{m_{k}+1}-x^{*}\right\|-\left\|x_{m_{k}}-x^{*}\right\| \\
& \leq\left\|x_{m_{k}}-x^{*}\right\|+\left\|x_{m_{k}+1}-x_{m_{k}}\right\| \rightarrow 0 \text { as } k \rightarrow \infty,
\end{aligned}
$$

which implies that $x_{k} \rightarrow x^{*}$ as $k \rightarrow \infty$. This completes the proof.

Corollary 1. Let $C$ be a nonempty closed and convex subset of a Hilbert space $H$. Let $T: C \rightarrow C$ be a nonexpansive self-mapping such that $F(T) \neq \varnothing$ and $f \in \Pi_{C}$ with coefficient $\alpha \in(0,1)$. For any $x_{1} \in C$, let $\left\{x_{n}\right\}$ be a sequence generated by:

$$
\left\{\begin{array}{l}
\bar{x}_{n+1}=\beta_{n} x_{n}+\left(1-\beta_{n}\right) T x_{n}, \\
x_{n+1}=\alpha_{n} f\left(x_{n}\right)+\left(1-\alpha_{n}\right) T\left(s_{n} x_{n}+\left(1-s_{n}\right) \bar{x}_{n+1}\right), \quad \forall n \geq 1,
\end{array}\right.
$$

where $\left\{\alpha_{n}\right\},\left\{\beta_{n}\right\}$, and $\left\{s_{n}\right\}$ belonging in $(0,1)$ satisfy $(C 1)$ and $(C 2)$ in Theorem 1. Then, the sequence $\left\{x_{n}\right\}$ converges strongly to $x^{*} \in F(T)$, which solves the variational inequality problem:

$$
\left\langle f\left(x^{*}\right)-x^{*}, z-x^{*}\right\rangle \leq 0, \forall z \in F(T) .
$$


Now, we give some remarks on our results as follows:

(1) We get the idea that the results of Ke and Ma [21] and Marino et al. [25] in Hilbert spaces extend to Banach spaces.

(2) The proof methods of our result are very different from the ones of Ke and Ma [21]. Further, we remove the following conditions:

$$
\sum_{n=1}^{\infty}\left|\alpha_{n+1}-\alpha_{n}\right|<\infty, \quad 0<\epsilon \leq s_{n} \leq s_{n+1}<1
$$

in Theorem 3.1 of [21].

(3) We give new control conditions and techniques to prove our results.

(4) The proof methods of our results are simpler than those of the results given by some authors (see, for example, $[8,21,36,37])$.

(5) Our results are applicable for the family of nonexpansive mappings, for example $W_{n}$-mapping, a countable family of nonexpansive mappings, and nonexpansive semigroups.

\section{Open Problem}

Is it possible to obtain the convergence results of the sequence (10) in the setting of more general spaces, such as reflexive, strictly-convex, and smooth Banach spaces, which admit the duality mapping $j_{\varphi}$ without the weak continuity assumption, where $\varphi$ is a gauge function?

\section{Convergence Theorems for a Strict Pseudo-Contraction Mapping}

Let $C$ be a closed, convex subset, and nonempty in $E$. A self-mapping $T$ is called $\lambda$-strictly pseudo-contractive if there exists $\lambda>0$ such that:

$$
\langle T x-T y, j(x-y)\rangle \leq\|x-y\|^{2}-\lambda\|(I-T) x-(I-T) y\|^{2}, \forall x, y \in C
$$

for some $j(x-y) \in J(x-y)$. It is easy to check that (28) is equivalent to the following inequality:

$$
\langle(I-T) x-(I-T) y, j(x-y)\rangle \geq \lambda\|(I-T) x-(I-T) y\|^{2}, \forall x, y \in C .
$$

Lemma 8. ([38]) Let $C$ be closed, convex subset and nonempty two-uniformly smooth in $E$. Let $T$ be a $\lambda$-strict pseudo-contractive mapping. For all $x \in C$, we define $T_{\theta} x:=(1-\theta) x+\theta T x$. Then, for any $\theta \in\left(0, \frac{\lambda}{K^{2}}\right]$, where $K>0$ is the two-uniformly smooth constant, $T_{\theta}$ is a nonexpansive mapping such that $F\left(T_{\theta}\right)=F(T)$.

Using Theorem 1 and Lemma 8, we get the result as follows:

Theorem 2. Let $C$ be a closed, convex subset and nonempty uniformly convex and two-uniformly smooth in $E$. Let $T$ be a $\lambda$-strict pseudo-contractions with $F(T) \neq \varnothing$ and $f \in \Pi_{C}$ with coefficient $\alpha \in(0,1)$. Define a mapping $T_{\theta} x:=(1-\theta) x+\theta T x$ for all $x \in C$, where $\theta \in\left(0, \frac{\lambda}{K^{2}}\right]$. For any $x_{1} \in C$, let $\left\{x_{n}\right\}$ be a sequence generated by:

$$
\left\{\begin{array}{l}
\bar{x}_{n+1}=\beta_{n} x_{n}+\left(1-\beta_{n}\right) T_{\theta} x_{n}, \\
x_{n+1}=\alpha_{n} f\left(x_{n}\right)+\left(1-\alpha_{n}\right) T_{\theta}\left(s_{n} x_{n}+\left(1-s_{n}\right) \bar{x}_{n+1}\right), \quad \forall n \geq 1,
\end{array}\right.
$$

where $\left\{\alpha_{n}\right\},\left\{\beta_{n}\right\}$, and $\left\{s_{n}\right\}$ belonging in $(0,1)$ satisfy $(C 1)$ and $(C 2)$ of Theorem 1 . Then, the sequence $\left\{x_{n}\right\}$ converges strongly to $x^{*} \in F(T)$, which solves the variational inequality problem:

$$
\left\langle f\left(x^{*}\right)-x^{*}, j\left(z-x^{*}\right)\right\rangle \leq 0, \forall z \in F(T) .
$$




\section{Some Applications}

In this section, we give some applications of Theorem 1 in the framework of Hilbert spaces.

\subsection{Periodic Solution of a Nonlinear Evolution Equation}

Let $H$ be a (possibly complex) Hilbert space. Consider the following time-dependent nonlinear evolution equation in $H$ :

$$
\frac{d u}{d t}+A(t) u=g(t, u), \quad \forall t>0
$$

where $A(t)$ is a family of closed, linear operators and $g: \mathbb{R} \times H \rightarrow H$. Recall that $u$ is a mild solution of Equation (31) with initial value $u(0)=v$ if, for any $t>0$,

$$
u(t)=U(t, 0) v+\int_{0}^{t} U(t, s) g(s, u(s)) d s,
$$

where $\{U(t, s)\}_{t \geq s \geq 0}$ is the evolution system in the case of a homogeneous linear system:

$$
\frac{d u}{d t}+A u(t)=0 .
$$
in [39].

The following useful result on the existence of periodic solutions of the problem (31) can be found

Theorem 3. Assume that $A(t)$ and $g(t, u)$ are periodic in $t$ of period $\xi>0$ and satisfy:

(1) $\operatorname{Re}\langle g(t, u)-g(t, v), u-v\rangle \leq 0 \forall t>0$ and $u, v \in H$;

(2) $u \in D(A(t))$ and $\operatorname{Re}\langle D(A(t)) u, u\rangle \geq 0 \forall t>0$;

(3) There exists a mild solution $u$ of the Equation (31) on $\mathbb{R}^{+}$for each initial value $v \in H$;

(4) There exists some $R>0$ such that $\operatorname{Re}\langle g(t, u), u\rangle<0$ for all $u \in H$ with $\|u\|=R$ and $t \in[0, \xi]$.

Then, there exists $v \in H$ with $\|v\| \leq R$ such that solution of Equation (31) with initial $u(0)=v$ is of period $\xi$.

If we define a mapping $T: H \rightarrow H$ by:

$$
T v=u(\xi), \forall v \in H,
$$

where $u$ is the solution of the Equation (31) satisfying initial $u(0)=v$, then $T$ is a nonexpansive of closed ball $B:=\{v \in H: v \leq R\}$ into itself with $F(T) \neq \varnothing$. Moreover, each fixed point of $T$ corresponding to solution $u$ of Equation (31) is the periodic solution of Equation (31) with the initial $u(0)=v$ (see [39]). For the other case, finding a periodic solution of (31) is equivalent to finding a fixed point set (see [40], Section 10).

Theorem 4. Let $H$ be a Hilbert space. Let $A(t)$ and $g(t, u)$ be periodic in $t$ of period $\xi>0$, which satisfy the conditions (i)-(iv) of Theorem 3. Let $T: H \rightarrow H$ be a mapping defined by (32) and $f \in \Pi_{H}$ with coefficient $\alpha \in(0,1)$. Suppose that $\left\{\alpha_{n}\right\},\left\{\beta_{n}\right\}$ and $\left\{s_{n}\right\}$ are the sequences in $(0,1)$ that satisfy the conditions $(C 1)$ and (C2) of Theorem 1. For any $x_{1} \in H$, let $\left\{x_{n}\right\}$ be a sequence generated by:

$$
\left\{\begin{array}{l}
\bar{x}_{n+1}=\beta_{n} x_{n}+\left(1-\beta_{n}\right) T x_{n}, \\
x_{n+1}=\alpha_{n} f\left(x_{n}\right)+\left(1-\alpha_{n}\right) T\left(s_{n} x_{n}+\left(1-s_{n}\right) \bar{x}_{n+1}\right), \quad \forall n \geq 1 .
\end{array}\right.
$$

Then, the sequence $\left\{x_{n}\right\}$ converges strongly to fixed element $v$ of $T$, and then, the corresponding solution of the Equation (31) with initial $u(0)=\xi$ is a periodic solution of Equation (31). 


\subsection{Nonlinear Fredholm Integral Equation}

Consider the following nonlinear Fredholm integral equation:

$$
x(t)=g(t)+\int_{0}^{1} F(t, s, x(s)) d s, \forall t \in[0,1],
$$

where $g$ is a continuous function on $[0,1]$.

$F:[0,1] \times[0,1] \times \mathbb{R} \rightarrow \mathbb{R}$ is a continuous function. In this case, if we assume that $F$ satisfies the Lipschitz continuity condition, i.e.,

$$
|F(t, s, x)-F(t, s, y)| \leq|x-y|, \quad \forall t, s \in[0,1], x, y \in \mathbb{R}
$$

then Equation (34) has at least one solution in $L_{2}[0,1]$ (see [41], Theorem 3.3). Define a mapping $T: L_{2}[0,1] \rightarrow L_{2}[0,1]$ by:

$$
(T x)(t)=g(t)+\int_{0}^{1} F(t, s, x(s)) d s, \quad \forall t \in[0,1] .
$$

Then, for any $x, y \in L_{2}[0,1]$, we have:

$$
\begin{aligned}
\|T x-T y\|^{2} & =\int_{0}^{1}|(T x)(t)-(T y)(t)|^{2} d t \\
& =\int_{0}^{1}\left|\int_{0}^{1}(F(t, s, x(s))-F(t, s, y(s))) d s\right|^{2} d t \\
& \leq \int_{0}^{1}\left|\int_{0}^{1}\right| x(s)-y(s)|d s|^{2} d t \\
& \leq \int_{0}^{1}|x(s)-y(s)|^{2} d s \\
& \leq\|x-y\|^{2},
\end{aligned}
$$

which implies that $T$ is a nonexpansive mapping on $L_{2}[0,1]$. Thus, we see that finding a solution of Equation (34) is equivalent to finding a fixed point of $T$ in $L_{2}[0,1]$.

Theorem 5. Let $F:[0,1] \times[0,1] \times \mathbb{R} \rightarrow \mathbb{R}$ be a mapping satisfying the Lipschitz continuity condition and $g$ be a continuous function on $[0,1]$. Let $T: L_{2}[0,1] \rightarrow L_{2}[0,1]$ be a mapping defined by $(36)$ and $f \in \Pi_{L_{2}}[0,1]$ with coefficient $\alpha \in(0,1)$. Suppose that $\left\{\alpha_{n}\right\},\left\{\beta_{n}\right\}$ and $\left\{s_{n}\right\}$ are the sequences in $(0,1)$ that satisfy the conditions $(C 1)$ and $(C 2)$ of Theorem 1. For any $x_{1}(t) \in L_{2}[0,1]$, let $\left\{x_{n}\right\}$ be a sequence generated by:

$$
\left\{\begin{array}{l}
\bar{x}_{n+1}(t)=\beta_{n} x_{n}(t)+\left(1-\beta_{n}\right) T x_{n}(t), \\
x_{n+1}(t)=\alpha_{n} f\left(x_{n}(t)\right)+\left(1-\alpha_{n}\right) T\left(s_{n} x_{n}(t)+\left(1-s_{n}\right) \bar{x}_{n+1}(t)\right), \quad \forall n \geq 1
\end{array}\right.
$$

where $t \in[0,1]$. Then, the sequence $\left\{x_{n}(t)\right\}$ converges strongly in $L_{2}[0,1]$ to the solution of the integral Equation (34).

Remark 1. Our result can be applied to show the existence of solutions of some nonlinear problems, that is (general system) variational inequality problems, constrained convex minimization problems, hierarchical minimization problems, and split feasibility problems (see [21,36,42]).

\section{Numerical Examples}

In this section, we present a numerical example of the sequence (10) in the $\ell_{3}$ space, which is uniformly convex with uniformly smooth setting of a Banach space, but not a Hilbert space. Further, 
using MATLAB, numerical results of the sequence (7) are obtained. In particular, we perform the comparison speed of the convergence to show that the sequence (10) is faster than the sequence (7).

Example 1. Let $C=E=\ell_{3}$ and $\mathbf{x}=\left(x_{1}, x_{2}, x_{3}, \cdots\right) \in \ell_{3}$, where $x_{i} \in \mathbb{R}$ for $i=1,2,3, \cdots$ and $\|\cdot\|_{\ell_{3}}: \ell_{3} \rightarrow \mathbb{R}^{+}$be the norm defined by:

$$
\|\mathbf{x}\|_{\ell_{3}}=\left(\sum_{i=1}^{\infty}\left|x_{i}\right|^{3}\right)^{1 / 3}
$$

Let $T: \ell_{3} \rightarrow \ell_{3}$ be a nonexpansive mapping and $f: \ell_{3} \rightarrow \ell_{3}$ be a contraction defined by:

$$
T \mathbf{x}=\left(\frac{x_{1}+x_{2}}{10}, \frac{x_{2}+x_{3}}{2}, \frac{x_{3}-x_{1}}{5}, 0,0,0, \cdots\right), \quad f(\mathbf{x})=\frac{1}{4}\left(x_{1}, x_{2}, x_{3}, \cdots\right),
$$

respectively. Let $\alpha_{n}=\frac{1}{10 n+1}, \beta_{n}=\frac{1}{20 n+1}+0.9$ and $s_{n}=\frac{1}{30 n+1}+0.8$. It is easy to see that the sequences $\left\{\alpha_{n}\right\},\left\{\beta_{n}\right\}$, and $\left\{s_{n}\right\}$ satisfy the conditions (C1) and (C2) of Theorem 1. Moreover, we have $F(T)=\{(0,0,0,0,0,0, \cdots)\}$. Therefore, our sequence (10) has the following form:

$$
\left\{\begin{array}{l}
\overline{\mathbf{x}}_{n+1}=\left(\frac{1}{20 n+1}+0.9\right) \mathbf{x}_{n}+\left(0.1-\frac{1}{20 n+1}\right) T \mathbf{x}_{n} \\
\mathbf{x}_{n+1}=\frac{1}{10 n+1} f\left(\mathbf{x}_{n}\right)+\frac{10 n}{10 n+1} T\left(\left(\frac{1}{30 n+1}+0.8\right) \mathbf{x}_{n}+\left(0.2-\frac{1}{30 n+1}\right) \overline{\mathbf{x}}_{n+1}\right), \quad \forall n \geq 1
\end{array}\right.
$$

and the sequence (7) has the following form:

$$
\mathbf{x}_{n+1}=\frac{1}{10 n+1} f\left(\mathbf{x}_{n}\right)+\frac{10 n}{10 n+1} T\left(\left(\frac{1}{30 n+1}+0.8\right) \mathbf{x}_{n}+\left(0.2-\frac{1}{30 n+1}\right) \mathbf{x}_{n+1}\right), \quad \forall n \geq 1 .
$$

Let $\mathbf{x}_{\mathbf{1}}=(1,-2,3,0,0,0, \cdots)$ be an initial point. Then, we obtain the following numerical results:

Remark 2. We see that from Tables 1 and 2 and Figure 1, the sequence (38) converges to a fixed point of $T$ faster than the sequence (39).

Table 1. Numerical results of the sequence (38).

\begin{tabular}{ccc}
\hline Number of Iterates & $\mathbf{x}_{n}=\left(x_{\mathbf{1}}^{n}, x_{\mathbf{2}}^{n}, x_{\mathbf{3}}^{n}, x_{4}^{n}, x_{5}^{n}, x_{\mathbf{6}}^{n}, \ldots\right)$ & $\left\|\mathbf{x}_{n}-\boldsymbol{F}(T)\right\|_{3}$ \\
\hline 1 & $(1.0000000,-2.0000000,3.0000000,0,0,0, \ldots)$ & 2.7144176 \\
2 & $(0.2327849,-0.4480184,0.7292703,0,0,0, \ldots)$ & 0.6771823 \\
3 & $(0.0526107,-0.0931765,0.1750471,0,0,0, \ldots)$ & 0.1675113 \\
4 & $(0.0118323,-0.0180499,0.0418631,0,0,0, \ldots)$ & 0.0410437 \\
5 & $(0.0026730,-0.0031216,0.0099981,0,0,0, \ldots)$ & 0.0099602 \\
6 & $(0.0006105,-0.0004172,0.0023865,0,0,0, \ldots)$ & 0.0023955 \\
7 & $\left(3.3678 \times 10^{-5}, 2.2004 \times 10^{-5}, 0.0001358,0,0,0, \ldots\right)$ & $1.3688 \times 10^{-4}$ \\
8 & $\left(8.2042 \times 10^{-6}, 1.1855 \times 10^{-5}, 3.2365 \times 10^{-5}, 0,0,0, \ldots\right)$ & $3.3056 \times 10^{-5}$ \\
9 & $\left(2.0542 \times 10^{-6}, 4.6141 \times 10^{-6}, 7.7051 \times 10^{-6}, 0,0,0, \ldots\right)$ & $8.2639 \times 10^{-6}$ \\
10 & $\vdots$ & $\vdots$ \\
$\vdots$ & $\left(2.8321 \times 10^{-9}, 1.3627 \times 10^{-8}, 5.6702 \times 10^{-9}, 0,0,0, \ldots\right)$ & $1.3986 \times 10^{-8}$ \\
\hline
\end{tabular}


Table 2. Numerical results of the sequence (39).

\begin{tabular}{ccc}
\hline Number of Iterates & $\mathrm{x}_{n}=\left(x_{1}^{n}, x_{2}^{n}, x_{3}^{n}, x_{4}^{n}, x_{5}^{n}, x_{6}^{n}, \ldots\right)$ & $\left\|\mathrm{x}_{n}-\boldsymbol{F}(T)\right\|_{3}$ \\
\hline 1 & $(1.0000000,-2.0000000,3.0000000,0,0,0, \ldots)$ & 2.7144176 \\
2 & $(-0.0470355,0.3985926,0.3853261,0,0,0, \ldots)$ & 0.4938371 \\
3 & $(0.0337876,0.3481921,0.0732708,0,0,0, \ldots)$ & 0.3493757 \\
4 & $(0.0344241,0.1863456,0.0570267,0,0,0, \ldots)$ & 0.1867381 \\
5 & $(0.0196135,0.0844269,-0.0054563,0,0,0, \ldots)$ & 0.0847707 \\
6 & $(0.0091690,0.0345417,-0.0045213,0,0,0, \ldots)$ & 0.0347302 \\
7 & $(0.0038295,0.0130688,-0.0024315,0,0,0, \ldots)$ & 0.0131499 \\
8 & $(0.0014729,0.0046081,-0.0011026,0,0,0, \ldots)$ & 0.0046371 \\
9 & $\left(5.2742 \times 10^{-4}, 0.0015100,-4.5084 \times 10^{-4}, 0,0,0, \ldots\right)$ & 0.0015180 \\
10 & $\left(1.7573 \times 10^{-4}, 4.5282 \times 10^{-4},-1.7034 \times 10^{-4}, 0,0,0, \ldots\right)$ & $4.5360 \times 10^{-4}$ \\
$\vdots$ & $\vdots$ & $\vdots$ \\
15 & $\left(-1.7307 \times 10^{-7},-1.6353 \times 10^{-6},-3.0799 \times 10^{-7}, 0,0,0, \ldots\right)$ & $8.1981 \times 10^{-7}$ \\
\hline
\end{tabular}

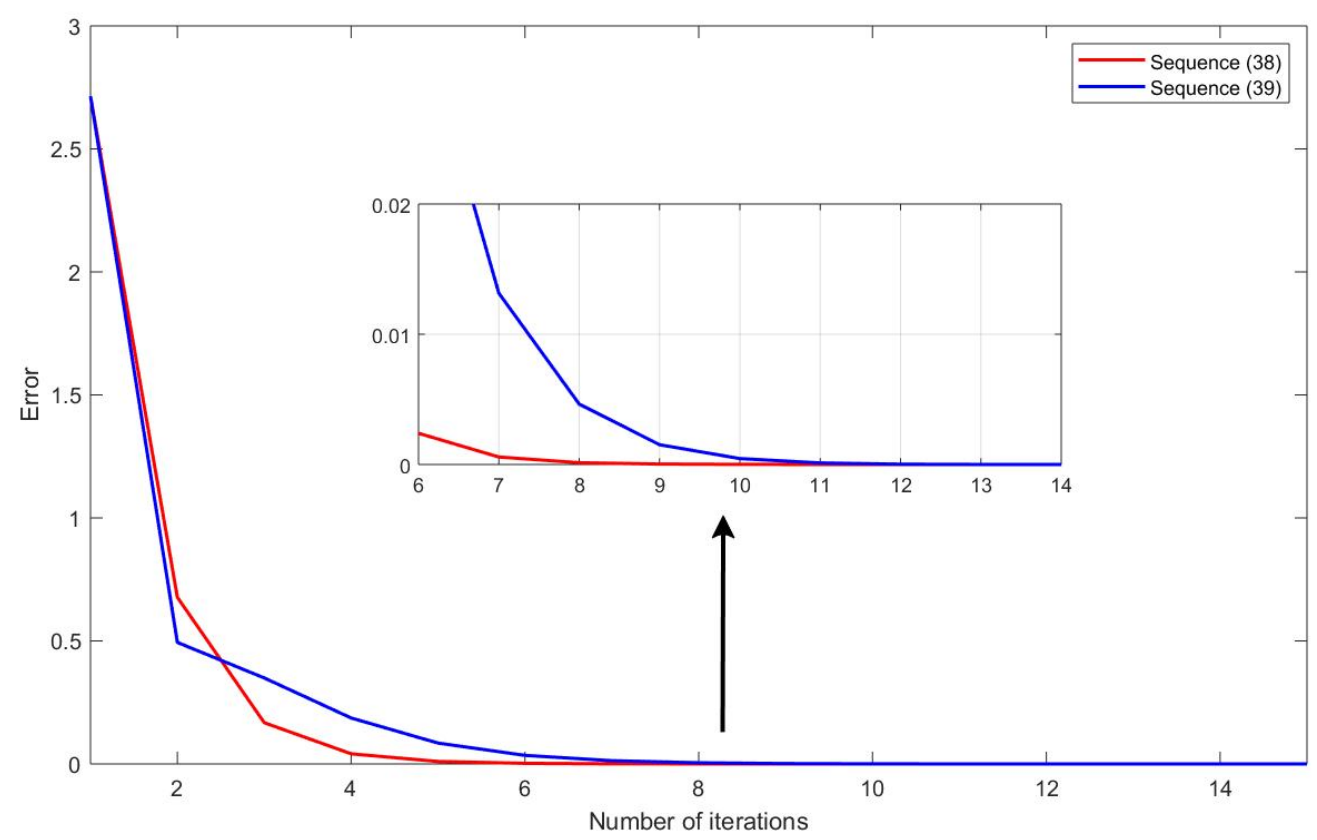

Figure 1. The convergence behavior of error values for the sequences (38) and (39).

Author Contributions: All authors read and approved the final manuscript.

Funding: Pongsakorn Sunthrayuth was supported by the RMUTTResearch Grant for New Scholars under Grant NSF62D0602. Nuttapol Pakkaranang to thank the Thailand Research Fund (TRF) and King Mongkut's University of Technology Thonburi (KMUTT) for their joint support through the Royal Golden Jubilee Ph.D. (RGJ-PHD) Program (Grant No. PHD/0205/2561). Phatiphat Thounthong was financially supported by King Mongkut's University of Technology North Bangkok, Contract No. KMUTNB-61-GOV-D-68. Prasit Cholamjiak was supported by the Thailand Research Fund and University of Phayao under Grant RSA6180084.

Acknowledgments: This project was supported by the Theoretical and Computation Science (TaCS) Center under Computational and Applied Science for Smart Innovation Cluster (CLASSIC), Faculty of Science, KMUTT. Moreover, this research work was financially supported by King Mongkut's University of Technology, North Bangkok, Contract No. KMUTNB-61-GOV-D-68.

Conflicts of Interest: The authors declare no conflict of interest. 


\section{References}

1. Auzinger, W.; Frank, R. Asymptotic error expansions for stiff equations: an analysis for the implicit midpoint and trapezoidal rules in the strongly stiff case. Numer. Math. 1989, 56, 469-499. [CrossRef]

2. Bader, G.; Deuflhard, P. A semi-implicit mid-point rule for stiff systems of ordinary differential equations. Numer. Math. 1983, 41, 373-398. [CrossRef]

3. Deuflhard, P. Recent progress in extrapolation methods for ordinary differential equations. SIAM Rev. 1985, 27, 505-535. [CrossRef]

4. Schneider, C. Analysis of the linearly implicit mid-point rule for differential-algebra equations. Electron. Trans. Numer. Anal. 1993, 1,1-10.

5. Somalia, S. Implicit midpoint rule to the nonlinear degenerate boundary value problems. Internat. J. Comput. Math. 2002, 79, 327-332. [CrossRef]

6. Veldhuxzen, M.V. Asymptotic expansions of the global error for the implicit midpoint rule (stiff case). Computing 1984, 33, 185-192. [CrossRef]

7. Hairer, E.; Nørsett, S.P.; Wanner, G. Solving Ordinary Differential Equations I: Nonstiff Problems, 2nd ed.; Springer Series in Computational Mathematics; Springer: Berlin, Germany, 1993.

8. Xu, H.K.; Alghamdi, M.A.; Shahzad, N. The viscosity technique for the implicit midpoint rule of nonexpansive mappings in Hilbert spaces. Fixed Point Theory Appl. 2015, 2015, 41. [CrossRef]

9. Moudafi, A. Viscosity approximation methods for fixed point problems. J. Math. Anal. Appl. 2000, $241,46-55$. [CrossRef]

10. Cho, Y.J.; Qin, X. Viscosity approximation methods for a finite family of $m$-accretive mappings in reflexive Banach spaces. Positivity 2008, 12, 483-494. [CrossRef]

11. Qin, X.; Cho, Y.J.; Kang, S.M. Viscosity approximation methods for generalized equilibrium problems and fixed point problems with applications. Nonlinear Anal. 2010, 72, 99-112. [CrossRef]

12. Wang, S.H.; Zhao, M.; Kumam, P.; Cho, Y.J. A viscosity extragradient method for an equilibrium problem and fixed point problem in Hilbert spaces. J. Fixed Point Theory Appl. 2018, 20, 19. [CrossRef]

13. Eshita, K.; Takahashi, W. Approximating zero points of accretive operators in general Banach spaces. J. Fixed Point Theory Appl. 2007, 2, 105-116.

14. Chen, R.; Song, Y.; Zhou, H. Convergence theorems for implicit iteration process for a finite family of continuous pseudocontractive mappings. J. Math. Anal. Appl. 2006, 314, 701-709. [CrossRef]

15. Agarwal, R.P.; O'Regan, D.; Sahu, D.R. Fixed Point Theory for Lipschitzian-Type Mappings with Applications; Springer: New York, NY, USA, 2009.

16. Censor, Y.; Elfving, T. A multiprojection algorithm using Bregman projections in a product space. Numer. Algorithms 1994, 8, 221-239. [CrossRef]

17. Byrne, C. A unified treatment of some iterative algorithms in signal processing and image reconstruction. Inverse Probl. 2008, 20, 103-120. [CrossRef]

18. $\mathrm{Xu}, \mathrm{H} . \mathrm{K}$. A variable Krasnoselskii-Mann algorithm and the multiple-set split feasibility problem. Inverse Probl. 2006, 22, 2021-2034. [CrossRef]

19. Censor, Y.; Bortfeld, T.; Martin, B.; Trofimov, A. A unified approach for inversion problems in intensitymodulated radiation therapy. Phys. Med. Biol. 2006, 51, 2353-2365. [CrossRef]

20. Alghamdi, M.A.; Shahzad, N.; Xu, H.K. The implicit midpoint rule for nonexpansive mappings. Fixed Point Theory Appl. 2014, 2014, 96. [CrossRef]

21. Ke, Y.; Ma, C. The generalized viscosity implicit rules of nonexpansive mappings in Hilbert spaces. Fixed Point Theory Appl. 2015, 2015, 190. [CrossRef]

22. Hoffman, J.D. Numerical Methods for Engineers and Scientists, 2nd ed.; Marcel Dekker, Inc.: New York, NY, USA, 2001.

23. Palais, R.S.; Palais, R.A. Differential Equations, Mechanics and Computation; American Mathematical Society: Providence, RI, USA, 2009.

24. Moaveni, S. Finite Element Analysis Theory And Application With Ansys, 3rd ed.; Pearson Education: London, UK, 2008.

25. Marino, G.; Scardamaglia, B.; Zaccone, R. A general viscosity explicit midpoint rule for quasi-nonexpansive mappings. J. Nonlinear Convex Anal. 2017, 18, 137-148.

26. Takahashi, W. Nonlinear Functional Analysis; Yokohama Publishers: Yokohama, Japan, 2000. 
27. Liu, L.S. Ishikawa and Mann iterative processes with errors for nonlinear strongly accretive mappings in Banach spaces. J. Math. Anal. Appl. 1995, 194, 114-125. [CrossRef]

28. Xu, H.K. Inequalities in Banach spaces with applications. Nonlinear Anal. 1991, 16, 1127-1138. [CrossRef]

29. Xu, H.K. Viscosity approximation methods for nonexpansive mappings. J. Math. Anal. Appl. 2004, 298, 279-291. [CrossRef]

30. Reich, S. Strong convergence theorems for resolvents of accretive operators in Banach spaces. J. Math. Anal. Appl. 1980, 75, 287-292. [CrossRef]

31. Kopecka, E.; Reich, S. Approximating fixed points in the Hilbert ball. J. Nonlinear Convex Anal. 2014, 15, 819-829.

32. Song, Y.; Chen, R.; Zhou, H. Viscosity approximation methods for nonexpansive mapping sequences in Banach spaces. Nonlinear Anal. 2007, 66, 1016-1024. [CrossRef]

33. Xu, H.K. Iterative algorithms for nonlinear operators. J. Lond. Math. Soc. 2002, 66, 240-256. [CrossRef]

34. Reich, S. Constructive Techniques for Accretive and Monotone Operator. In Applied Nonlinear Analysis; Academic Press: Cambridge, MA, USA, 1979; pp. 335-345.

35. Maingé, P.E. Strong convergence of projected subgradient methods for nonsmooth and nonstrictly convex minimization. Set-Valued Anal. 2008, 16, 899-912. [CrossRef]

36. Yao, Y.; Shahzad, N.; Liou, Y.C. Modified semi-implicit midpoint rule for nonexpansive mappings. Fixed Point Theory Appl. 2015, 2015, 166. [CrossRef]

37. Luo, P.; Cai, G.; Shehu, Y. The viscosity iterative algorithms for the implicit midpoint rule of nonexpansive mappings in uniformly smooth Banach spaces. J. Inequal. Appl. 2017, 2017, 154. [CrossRef]

38. Zhou, H. Convergence theorems for $\lambda$-strict pseudo-contractions in 2-uniformly smooth Banach spaces. Nonlinear Anal. 2008, 69, 3160-3173. [CrossRef]

39. Browder, F.E. Existence of periodic solutions for nonlinear equations of evolution. Proc. Natl. Acad. Sci. USA 1965, 53, 1100-1103. [CrossRef] [PubMed]

40. Goebel, K.; Reich, S. Uniform Convexity, Hyperbolic Geometry, and Nonexpansive Mappings; Series of Monographs and Textbooks in Pure and Applied Mathematics; Dekker: New York, NY, USA, 1984.

41. Nieto, J.J.; Xu, H.K. Solvability of nonlinear Volterra and Fredholm equations in weighted spaces. Nonlinear Anal. 1995, 24, 1289-1297. [CrossRef]

42. Sunthrayuth, P.; Cho, Y. J.; Kumam, P. General iterative algorithms approach to variational inequalities and minimum-norm fixed point for minimization and split feasibility problems. OPSEARCH 2014, 51, 400-415. [CrossRef]

(C) 2019 by the authors. Licensee MDPI, Basel, Switzerland. This article is an open access article distributed under the terms and conditions of the Creative Commons Attribution (CC BY) license (http://creativecommons.org/licenses/by/4.0/). 